\title{
Abuse of over-the-counter medicines: a pharmacist's perspective
}

\section{Sujit S Sansgiry \\ Archita H Bhansali \\ Shweta S Bapat \\ Qingqing Xu}

Pharmaceutical Health Outcomes and Policy, College of Pharmacy, University of Houston, Houston, TX, USA

Correspondence: Sujit S Sansgiry Pharmaceutical Health Outcomes and Policy, College of Pharmacy, University of Houston, I44I Moursund Street, Houston, TX 77030, USA

$\mathrm{Tel}+\mathrm{I} 8328428392$

Fax +l 8328428383

Email ssansgiry@uh.edu
This article was published in the following Dove Press journal:

Integrated Pharmacy Research and Practice

19 December 2016

Number of times this article has been viewed

Abstract: Self-care and self-medication practices are essential components of any health care systems. The use of over-the-counter (OTC) medications is a part of the self-medication process. The popularity of OTC medication use among patients may increase the abuse potential of OTC medications. With pharmacists being as accessible as they are, they are often the first line of contact for patients, and have the opportunity to educate and counsel patients on appropriate OTC medication use. The presence of a pharmacist ensures safe and effective use of OTC medications. Pharmacists can liaise with other health care providers in the management of self-care practices by patients. However, a pharmacist has traditionally been underutilized in this role. This article provides a brief review on OTC medications with abuse potential and the effect of self-medication on OTC medication abuse. This review further describes the barriers faced by pharmacists in OTC medication abuse management, given the increased potential of prescription-to-OTC switch in recent years. In addition, the potential for a behind-the-counter drug category to boost patient-pharmacist interaction was discussed. The current review supports the positive role played by pharmacists in the management of OTC medication abuse. This review adds to the knowledge base of the barriers faced by pharmacists to prevent OTC medication abuse while developing appropriate intervention strategies. By expanding the role of pharmacists, OTC medication abuse may be controlled more effectively, thereby providing better patient medication therapy management and outcomes.

Keywords: non-prescription, behind-the-counter, medication, self-medication

\section{Introduction}

Medications obtained by patients for treatment of common ailments, without a prescription from a physician, are known as over-the-counter (OTC) or non-prescription medications. OTC medications provide prevention and treatment for a wide range of conditions, including but not limited to headaches, common cold, musculoskeletal pain, allergies, tobacco dependence, and heartburn. ${ }^{1}$ However, there is always a risk involved in using OTC medications. ${ }^{1,2}$ These include improper self-diagnosis, inappropriate dosage, addiction issues upon prolonged use, adverse drug reactions, and drug interactions. ${ }^{3,4} \mathrm{As}$ most patients do not discuss their OTC medications with a physician, they are unaware of the risks associated with OTC medications. ${ }^{5}$ In addition, direct-to-patient advertising increases the exposure of medications to patients. ${ }^{5}$ As a result, there is increased product use in the absence of professional help. ${ }^{4,6}$ OTC medication abuse for the purpose of this review is defined as the use of non-prescription medications for non-medical purposes. ${ }^{7}$ Abuse is often intentional, unlike OTC medication misuse, which may be medication used for medical purposes but used incorrectly, for example, incorrect dosage, lack of interactions knowledge, inappropriate medication use, and incorrect duration of use. ${ }^{8}$ 
However, there is a growing concern of the potential harm associated with these medications. The objective of this article is to provide a brief review of the OTC medication abuse, extent of the OTC medication abuse, the role of pharmacists to address this issue, the concept of behind-thecounter (BTC) medications, and needed future steps that must be taken by pharmacists and the pharmacy profession to curb the issue with nationwide impact. While there have been articles studying the OTC medications and abuse, very few have reviewed the barriers faced by pharmacists and the steps to prevent abuse from a pharmacy-based approach. This review will provide pharmacists and researchers a perspective to consider the possible role played by pharmacist in reducing OTC medication abuse and how strategies can be implemented to reduce it further.

\section{OTC medication abuse OTC medications with most potential for abuse}

Multiple OTC medications have abuse potential. Commonly abused medications include antihistamines, sleep aids, caffeine, ephedrine, pseudoephedrine, antitussives and expectorants, dextromethorphan, laxatives, anabolic steroids, and sildenafil..$^{9-11}$ Laxatives are abused for weight loss and high antihistamines doses are used for euphoria. ${ }^{12}$ From the studies done across the world for OTC medication abuse, opiate-based combination products and cough/ cold products containing dextromethorphan, sleep aids, antihistamines, analgesic, hypnotics, and laxatives have been highlighted as having abuse potential. Cough medicines and painkillers are most abused medications. OTC codeine or other opiate-containing products and OTC cough and cold medications are the most commonly implicated medications for abuse. ${ }^{7,13,14}$ Codeine is not available as OTC in the US. However, it is a primary medicine with abuse potential in other countries..$^{15}$ Numerous studies have recorded OTC codeine analgesics as the most commonly abused medication. ${ }^{6,16,17}$ Table 1 highlights the OTC medications with high abuse potential.

One of the probable reasons for OTC abuse is increased access to medications. This is because medications for common illnesses are made accessible by prescription ( $\mathrm{Rx})$ to-OTC switch. ${ }^{16}$ Most switches are driven by firm's patent expiration. However, in case of prescription antihistamines like Claritin, Zyrtec, and Allegra, Blue Cross and their parent company petitioned the switch to the US Food and Drug Administration (FDA) ${ }^{17}$ Providing patients with autonomy, diagnosis of the condition on the patient's judgment and the
Table I List of over-the-counter medications abused

\begin{tabular}{|c|c|}
\hline Class/therapeutic group & Medication example \\
\hline Antihistamines $^{40,41}$ & Diphenhydramine and coricidin \\
\hline Cough medicines ${ }^{42}$ & $\begin{array}{l}\text { Cough medicines containing } \\
\text { dextromethorphan }\end{array}$ \\
\hline Codeine-containing products ${ }^{7}$ & $\begin{array}{l}\text { Compound analgesics (codeine } \\
\text { with ibuprofen or paracetamol) and } \\
\text { cough medicines }\end{array}$ \\
\hline Analgesics $^{43}$ & Aspirin and acetaminophen \\
\hline Hypnotics $^{40}$ & Sominex and nytol \\
\hline Laxatives (oral and rectal) 7,44 & $\begin{array}{l}\text { Sodium phosphate laxatives and } \\
\text { laxatives containing bisacodyl }\end{array}$ \\
\hline Decongestants ${ }^{45}$ & Pseudoephedrine \\
\hline
\end{tabular}

absence of a physician may lead to inaccurate self-diagnosis. ${ }^{5}$ For example, the availability of treatment for dyspepsia masks the presence of a severe gastrointestinal disease, which may not be diagnosed by patients. ${ }^{16}$ Lack of pharmacist vigilance may lead to long-term inappropriate use of OTC medications and hamper the health of patients. ${ }^{5}$

Switching of drugs increases patient autonomy while encouraging them to make their health care decisions. ${ }^{16}$ About $\$ 12.9$ billion savings were recorded for the switch of cold/allergy, analgesics, and dermal products. ${ }^{18}$ However, this increasing number of medications being switched to OTC status increased the spectrum of medications available for abuse. ${ }^{19}$ For example, the switch of acetaminophen from prescription to OTC has led to increased cases of severe liver hepatotoxicity. ${ }^{20}$ If abused, acetaminophen leads to withdrawal symptoms, in addition to suicidal thoughts and liver failure.

\section{Role of pharmacist in OTC medications}

Patients have easy and free access toward seeking advice from a pharmacist. Many issues faced by a patient can be easily solved by pharmacists, including product selection, OTC brand name confusion, appropriate product use, and when to take medications. Thus, pharmacists exercise a strong influence on OTC medication purchase and product selection.

Many patients find product selection confusing due to marketing strategies by manufacturers. A common marketing technique by pharmaceutical manufacturers is line extension. ${ }^{5} \mathrm{~A}$ large percent of revenue is spent on OTC medication advertisements and line extensions. Once a manufacturer has an established brand name, other products are sold under the extension of the same brand. For example, the primary brand Tylenol ${ }^{\circledR}$ has many line extensions including Tylenol $\mathrm{PM}^{\circledR}$, and Tylenol Cold and $\mathrm{Cough}^{\circledR}$. This often leads to confusion among the minds of patients. Many times these line extensions have multiple ingredients causing more confusion. 
A patient-pharmacist interaction would help patients in their decision-making process during these instances.

OTC advertisements are often the driving factor in OTC medication selection by the patients. If the advertisements are misleading, a patient may be misinformed. ${ }^{21}$ The advertisements focus upon the beneficial effects of the medication with bare information on the contraindications and safety concerns. With this regard, a pharmacist can also provide insight into all aspects of the drug, as well as information on the safe use of OTC medications. ${ }^{19,22}$

\section{Pharmacy-based efforts to address OTC medication abuse Pharmacist's role in OTC medication abuse}

Historically, pharmacists focused on the medication distribution system. Over the past years, with the rising incidence of chronic illness, increased need for preventive services, and complex use of medications, both pharmacists and pharmacy technicians are expected to provide broader services. They assume more clinically patient-oriented roles. ${ }^{14}$ Within a hospital setting, certified pharmacy technicians have demonstrated positive impacts by obtaining medication history and conducting medication reconciliation for patients. ${ }^{7,15,23-25}$ Furthermore, pharmacy technicians help with care transitions from the hospital setting to the home and community settings. ${ }^{26}$ The dynamic environment of the health care system demands to expand the role of a pharmacist and pharmacy technician.

Pharmacists are the first point of contact during the purchase of OTC medications. They are required to monitor OTC medication use among a specific population. ${ }^{7}$ For example, in the case of elderly patients, who take multiple medications, pharmacists should be more vigilant. Also, patients who come in with request for frequent refills must be monitored as well including OTC medications used. ${ }^{27}$ Pharmacists can be more proactive in managing OTC medication abuse by utilizing their clinical skills, by providing oral and written medication information, and by developing trust among patients. ${ }^{23,28}$ Programs like prescription drug monitoring log information about a patient upon refills of prescription drugs. While if a similar program were set up for OTC medications, the person would have to visit the same pharmacy always. Hence, implementation of such a program may not be pragmatic.

Several methods employed by pharmacists to reduce OTC medication abuse have been suggested in the past. ${ }^{28}$ The top three methods used by pharmacists to control OTC medication abuse were keeping the implicated products out of sight, questioning on the purchase of these products by pharmacists, and refusal to sell the implicated product. ${ }^{3,29}$ It was demonstrated that $62 \%$ of pharmacists reported certain measures being taken to curb OTC medication abuse, for instance, not displaying medicines, refusing sales, and associated policies including pharmacist's conducting an interview of the patient. The interview may include asking additional questions to patients at the time of purchase and providing advice to patients as necessary to reduce abuse of potential products. ${ }^{24}$ Some other techniques used and reported by pharmacists to reduce OTC medication abuse were referral to a physician, referral to a drug and alcohol abuse team, and/or involvement of pharmacists in harm reduction programs. ${ }^{17}$ Table 2 lists the strategies that can be adopted in different locations and scenarios to curb OTC abuse.

\section{Barriers for pharmacists to prevent OTC medication abuse}

There are multiple challenges faced by pharmacists and their pharmacies in monitoring OTC abuse. Due to lack of consistent data with OTC medications, identification of drug-related problems may become difficult. Pharmacists usually never keep any record or monitor patient medication profiles for OTC medication use, which creates a vacuum in the information necessary to make appropriate counseling decisions. ${ }^{30}$

An individual seeking to abuse an OTC medication could probably obtain it from the same pharmacy at different times or visit different pharmacies for the same medication. However, considering this potential to abuse medications,

Table 2 Common strategies used by pharmacists to control over-the-counter medication abuse

\begin{tabular}{ll}
\hline Target locations & Pharmacist-initiatied strategies \\
\hline In a pharmacy & Refusing sales \\
Contacting other pharmacies to warn \\
them of the suspicions of a customer \\
who may be abusing a product \\
Claiming products were not in stock \\
Prevent supplies by hiding medicines \\
Supplying only limited amounts \\
Counseling customers about the abuse \\
Patient involvement & Raising awareness of Internet-based \\
& support groups among patients by \\
Physician involvement & advising them \\
and other services & Woviding information leaflets \\
& engagement/consultation \\
& Providing referral to doctors \\
& Using private clinic services \\
& Using specialist drug services and drug \\
and alcohol treatment services
\end{tabular}

Note: Data from Cooper $^{7}$ and Paulose-Ram et al. ${ }^{46}$ 
specifically pseudoephedrine, US federal government passed the Combat Methamphetamine Epidemic Act of 2005 (CMEA). This act was passed to monitor the amount of pseudoephedrine which an individual can purchase in a pharmacy in the US. ${ }^{31}$ The aim of this act was to curb illegal consumption of methamphetamine which can be bulk produced using drugs like ephedrine and pseudoephedrine that are commonly found in OTC cough and cold medications. The CMEA has placed a purchase limit of no more than $9 \mathrm{~g}$ of pseudoephedrine in a 30-day period. ${ }^{31}$ Although this act has successfully helped reduce the issue of OTC medication abuse of pseudoephedrine-containing products, adaptation of this process for other medications proactively by pharmacists has been non-existent in the US.

In addition, the lack of pharmacist's proactive initiatives to monitor patient's OTC medication use has led to many abuse opportunities. Pharmacists are usually overworked and the continuous high stress prescription processing workload also reduces the potential opportunities to be pharmaco-vigilant. Further, the legal requirements associated with medication distribution have not kept up with the abuse potential nor are the laws for the practice of pharmacy revised or kept up with patient or pharmacist needs. ${ }^{30}$

For example, a study conducted in a community pharmacy indicated that pharmacists were overworked. ${ }^{32}$ The lack of workforce in a pharmacy led to reduced attention and problem identification among the patient's OTC decisions. ${ }^{32}$ Further, the role of pharmacy technicians has not been adequately utilized to improve the practice of pharmacy. Due to limited number of pharmacists, pharmacy technicians are an important aspect in preventing OTC medication abuse as well. Pharmacy technicians provide an extra layer for patient safety. They can help pharmacists with roles like drug dispensing, obtaining patient information, and processing order entry. Their vigilance during these processes may further help in reducing OTC medication abuse. ${ }^{32}$

There are several programs in place to counter prescription drug abuse; OTC medication abuse has been overlooked. Pharmacy take back programs, drug monitoring programs as well as vigilance of professional pharmacy programs like the American Pharmacists Association (APHA) have been notable in the past few years and little focus has been provided for OTC medication abuse.

\section{BTC medications: a promising third class}

BTC medications are defined as "a third category of drugs available without a prescription; placed BTC, they are available only after consultation with a pharmacist.. ${ }^{33}$ BTC medications are widely adopted in many countries including the UK, Ireland, Canada, New Zealand, France, and Australia. ${ }^{34-36}$

The need for a BTC category was first assessed in 1995 by the Government Accountability Office (GAO) in the US while it was rejected by the FDA at that time. In 2007, the idea was re-proposed by the FDA and then reevaluated by GAO in 2009, without any conclusive statement. The FDA requested comprehensive evidence about the role that a potential BTC category would play in the US since 2007.

To distinguish from OTC medications, the characteristics of BTC medications are dispensing only with professional supervision. This ensures the safety, appropriateness, effectiveness of the dispensed medication, and increased control over medications with high clinical risk. ${ }^{37}$ However, implementation of BTC medication requires pharmacists and technicians to be qualified to perform initial assessments and screenings, medication reviews, patient counseling, and medication monitoring.

Some of the medications potential for transition to BTC category include those used for high blood pressure, high cholesterol, asthma, gastrointestinal reflux, allergies, and pain. ${ }^{37}$ To name a few as examples, aspirin/hydrocodone and nabilone (antiemetic) are listed as schedule II drugs in Canada, the counterpart of a BTC category, and children's cough and cold medications were recommended to be included into BTC by pharmacists for safety consideration. ${ }^{38} \mathrm{~A}$ similar class is required within the US. The current OTC medications with high abuse potential should be included under this medication class. Table 3 provides a list of medications that could be moved to BTC.

Despite the seemingly attractive prospects of BTC medication, including the potential to reduce medication abuse, the implementation of BTC medication category is controversial among primary stakeholders. Considering the safety and effectiveness of BTC medications, the Consum-

Table 3 Medications potential for transition to behind-the-counter category

\begin{tabular}{|l|l|}
\hline Indication of medication & Example \\
\hline High cholesterol & Statins $^{47,48}$ \\
\hline Blood sugar level maintaining & Insulin $^{49}$ \\
\hline Cold remedies & Pseudoephedrine and ephedrine ${ }^{48-50}$ \\
\hline Schedule V cough syrups & $\begin{array}{l}\text { Certain codeine-containing } \\
\text { products }^{49,50}\end{array}$ \\
\hline Emergency contraceptives & Plan B $^{48,49}$ \\
\hline Painkillers & $\begin{array}{l}\text { Painkillers with small amounts of } \\
\text { codeine (up to I } 2.8 \text { mg per tablet) } \\
\text { and aspirin }\end{array}$ \\
\hline Sleep aid/allergy & Diphenhydramine \\
\hline
\end{tabular}


ers Union and the National Consumers League argued for supportive evidence to make a national move to develop a third category, while the Consumers Healthcare Products Association (CHPA) opposed it. Physician organizations questioned the adequacy of pharmacists to provide clinical services, with a primary concern about the impact of BTC on physician-patient relationship. However, majority of pharmacy organizations provided a strong backing to the implementation of BTC medication. ${ }^{39}$

To facilitate the implementation of BTC medication category, the following recommendations were made: demonstration of benefits outweighing the risks, evidence for positive outcomes, financial savings to society, sufficient allocation of resources, and appropriate compensation systems. ${ }^{37}$ The BTC medication class provides adequate opportunities for pharmacists to reduce OTC medication abuse. The FDA should consider the BTC medication category to reduce OTC medication abuse.

\section{Role of pharmacists in BTC medications}

The presence of a pharmacist would be essential to purchase a BTC medication. These medications should be provided only upon a pharmacist's recommendation. Upon performing the necessary tests, initial screenings and appropriate counseling a BTC medication can be dispensed. Some of the potential candidates could be patients with high blood pressure, gastrointestinal reflux, asthma, severe allergies, and pain. ${ }^{5,37}$ All current OTC medications with high abuse potential can be included as BTC medications. If the pharmacists work collaboratively with their patients, it will lead to informed decision making and safer use of medications. Once a pharmacist disapproves a particular medication, they should refuse to dispense it. BTC medication is a bridge between OTC and prescription medications, with a potential to increase access of health care while efficiently using the knowledge and expertise of a pharmacist.

\section{Conclusion}

This review concludes that pharmacists need to be well informed of the OTC medications which have an abuse potential. Better communication strategies between pharmacists and patients may help pharmacists understand the issues of OTC medication abuse. OTC medicine abuse was identified in many countries. The implementation of a new class of BTC medications will help improve patient monitoring while curbing potential OTC medication abuse.

Pharmacists do play an essential role in counseling patients. Pharmacist vigilance can help reduce OTC medication abuse. The current health care system calls for more regulation on OTC medications, especially those with identified abuse potential. We need to strike a balance between providing the required access to medications and at the same time managing the risk of OTC medication abuse. Finally, the data collection and reporting for OTC medication abuse can be standardized with distinctive reporting for medication misuse, abuse, and addiction.

\section{Disclosure}

The authors report no conflicts of interest in this work.

\section{References}

1. Anderson JG. Demographic factors affecting health services utilization: a causal model. Med Care. 1973;11(2):104-120.

2. Wazaify M, Shields E, Hughes CM, McElnay JC. Societal perspectives on over-the-counter (OTC) medicines. Fam Pract. 2005;22(2):170-176.

3. Hughes CM, McElnay JC, Fleming GF. Benefits and risks of self medication. Drug Saf. 2001;24(14):1027-1037.

4. Bond C, Hannaford P. Issues related to monitoring the safety of overthe-counter (OTC) medicines. Drug Saf. 2003;26(15):1065-1074.

5. Sansgiry SS, Patel HK. Nonprescription Drugs. In: Swarbrick J, editor. Encyclopedia of Pharmaceutical Science and Technology. Fourth Edition. Boca Raton, FL: CRC Press; 2013.

6. Aronson J. Over-the-counter medicines. Br J Clin Pharmacol. 2004; 58(3):231-234.

7. Cooper RJ. 'I can't be an addict. I am.' Over-the-counter medicine abuse: a qualitative study. BMJ Open. 2013;3(6):e002913.

8. Hall GC, Sauer B, Bourke A, Brown JS, Reynolds MW, LoCasale R. Guidelines for good database selection and use in pharmacoepidemiology research. Pharmacoepidemiol Drug Saf. 2012;21(1):1-10.

9. Williams JF, Kokotailo PK. Abuse of proprietary (over-the-counter) drugs. Adolesc Med Clin. 2006;17(3):733-750; abstract xiii.

10. Tseng YL, Hsu H-R, Kuo F-H, Shieh MH, Chang CF. Ephedrines in over-the-counter cold medicines and urine specimens collected during sport competitions. J Anal Toxicol. 2003;27(6):359-365.

11. Tinsley JA, Watkins DD. Over-the-counter stimulants: abuse and addiction. Mayo Clinic Proc. 1998:73(10):977-982.

12. Sansgiry SS, Nadkarni A, Doan T. Misuse of over-the-counter medications among community-dwelling older adults and associated adverse drug events. J Pharmaceutical Health Serv Res. 2010;1(4):175-179.

13. Murphy JC. Americans make choices about self-care. Am J HealthSystPharm. 2001;58(16):1494.

14. Derry S, Moore RA, McQuay HJ. Single dose oral codeine, as a single agent, for acute postoperative pain in adults. Cochrane Database Syst Rev. 2010;(4):CD008099.

15. McBride AJ, Pates R, Ramadan R, McGowan C. Delphi survey of experts' opinions on strategies used by community pharmacists to reduce over-the-counter drug misuse. Addiction. 2003;98(4):487-497.

16. Soller RW. Evolution of self-care with over-the-counter medications. Clin Ther. 1998;20:C134-C140.

17. Eickhoff C, Hämmerlein A, Griese N, Schulz M. Nature and frequency of drug-related problems in self-medication (over-the-counter drugs) in daily community pharmacy practice in Germany. Pharmacoepidemiol Drug Saf. 2012;21(3):254-260.

18. Soller R. OTCness: Then and now. Pharm Med Pack News. 1998;6:16.

19. Brass EP. Changing the status of drugs from prescription to over-thecounter availability. $N$ Engl J Med. 2001;345(11):810-816.

20. Larson AM, Polson J, Fontana RJ, et al. Acetaminophen-induced acute liver failure: results of a United States multicenter, prospective study. Hepatology. 2005;42(6):1364-1372.

21. Covington T. Self-care and nonprescription pharmacotherapy. Am J Pharm Association. 2000:3-14. 
22. Mercola J, Droege R. Seven common misconceptions about Tylenol and other OTC drugs; 2004. Available from: http://www.mercola.com/2004/ feb/7/over_the_counter.htm. Accessed November 23, 2011.

23. Roussin A, Bouyssi A, Pouché L, Lapeyre-Mestre M. Misuse and dependence on non-prescription codeine analgesics or sedative $\mathrm{H} 1$ antihistamines by adults: a cross-sectional investigation in France. PLoS One. 2013;8(10):e76499.

24. Romanelli F, Smith KM. Dextromethorphan abuse: clinical effects and management. J Am Pharm Assoc (2003). 2009;49(2):e20-25.

25. Reed K, Bond A, Witton J, et al. The changing use of prescribed benzodiazepines and z-drugs and of over-the-counter codeine-containing products in England: a structured review of published English and international evidence and available data to inform consideration of the extent of dependence and harm. London: The National Addiction Centre, Kings College London; 2011.

26. Abuse (drug, alcohol, chemical, substance or psychoactive substance). Available from: http://www.who.int/substance_abuse/terminology/ abuse/en/. Accessed May 16, 2016.

27. American Pharmacists Association. 2006. Avoiding Medication Errors. Available from: http://www.pharmacist.com/AM/Template.cfm?Section $=$ Search1\&template $=/$ CM/HTMLDisplay.cfm \&ContentID=3546. Accessed November 25, 2011.

28. Major C, Vincze Z. Consumer habits and interests regarding nonprescription medications in Hungary. Fam Pract. 2010;27(3): 333-338.

29. Hughes CM. Monitoring self-medication. Expert Opin Drug Saf. 2003;2(1):1-5.

30. Hämmerlein A, Griese N, Schulz M. Survey of drug-related problems identified by community pharmacies. Ann Pharmacother. 2007;41(11): 1825-1832.

31. Murty S, Sansgiry SS. Pseudoephedrine laws in the US - are we doing enough? Ann Pharmacother. 2006;40(6):1213-1214.

32. Westerlund T, Almarsdóttir AB, Melander A. Drug-related problems and pharmacy interventions in community practice. Int J Pharm Pract. 1999;7(1):40-50.

33. Sega T, Sullivan DL. Assessment of pharmacists' opinions toward the behind-the-counter category of medications. J Am Pharm Assoc (2003). 2011;51(4):535-538.

34. Roerig JL, Steffen KJ, Mitchell JE, Zunker C. Laxative abuse: epidemiology, diagnosis and management. Drugs. 2010;70(12):1487-1503.

35. Benrimoj SI, Gilbert A, Emmerton L, et al. A cost-benefit analysis of Pharmacist Only (S3) and Pharmacy (S2) Medicines and risk-based evaluation of the standards; 2005.

36. Emmerton L. The 'third class' of medications: sales and purchasing behavior are associated with pharmacist only and pharmacy medicine classifications in Australia. J Am Pharm Assoc (2003). 2009;49(1): 31-37.
37. Ried LD, Huston SA, Kucukarslan SN, Sogol EM, Schafermeyer KW, Sansgiry SS. Risks, benefits, and issues in creating a behind-the-counter category of medications. J Am Pharm Assoc (2003). 2011;51(1):26-39.

38. Leslie SR, Gwadry-Sridhar F, Thiebaud P, Patel BV. Calculating medication compliance, adherence and persistence in administrative pharmacy claims databases. Pharma Prog. 2008;1(1):13-19.

39. Sweileh WM, Arafat RT, Al-Khyat LS, Al-Masri DM, Jaradat NA. A pilot study to investigate over-the-counter drug abuse and misuse in Palestine. Saudi Med J. 2004;25(12):2029-2032.

40. Griffiths RR, Johnson MW. Relative abuse liability of hypnotic drugs: a conceptual framework and algorithm for differentiating among compounds. J Clin Psychiatry. 2005;66(Supp1 9):31-41.

41. Baker SD, Borys DJ. A possible trend suggesting increased abuse from Coricidin exposures reported to the Texas Poison Network: comparing 1998 to 1999. Vet Hum Toxicol. 2002;44(3):169-171.

42. Miech RA, Johnston LD, O'malley PM, Bachman JG, Schulenberg JE. "Monitoring the future - National survey results on drug use,1975-2014. Bethseda, MD: National institute on Drug Abuse; National Institutes of Health; US Department of Health and Human Services; 2007.

43. Lessenger JE, Feinberg SD. Abuse of prescription and over-the-counter medications. J Am Board Fam Med. 2008;21(1):45-54.

44. Pomeranz JL, Taylor LM, Austin SB. Over-the-counter and out-ofcontrol: legal strategies to protect youths from abusing products for weight control. Am J Public Health. 2013;103(2):220-225.

45. Albsoul-Younes A, Wazaify M, Yousef A-M, Tahaineh L. Abuse and misuse of prescription and nonprescription drugs sold in community pharmacies in Jordan. Subst Use Misuse. 2010;45(9):1319-1329.

46. Paulose-Ram R, Hirsch R, Dillon C, Losonczy K, Cooper M, Ostchega Y. Prescription and non-prescription analgesic use among the US adult population: results from the third National Health and Nutrition Examination Survey (NHANES III). Pharmacoepidemiol Drug Saf. 2003;12(4):315-326.

47. Ried LD, Huston SA, Kucukarslan SN, Sogol EM, Schafermeyer KW, Sansgiry SS. Risks, benefits, and issues in creating a behind-the-counter category of medications. JAm Pharm Assoc (2003). 2011;51(1):26-39.

48. Senak M. Behind-the-Counter Drug Access. Am Health Drug Benefits. 2008;1(2) 56-57.

49. Pray WS, Pray GE. Behind-the-counter products: a third class of drugs. US Pharm. 2011;36(9):11-15.

50. Huston SA, Porter KB, Clements T, Shepherd G. Pharmacists' attitudes towards pediatric cough and cold products and behind the counter status. J Pediatric Pharmacol Ther. 2010;15(2):126-137.

51. Nonprescription drugs: considerations regarding a behind-the-counter drug class. In: Office GA, ed. Washington, DC: Government Accountability Office; 2009.

52. Alphabetical list of medicines for human use. Royal Pharmaceutical Society; 2010.
Integrated Pharmacy Research and Practice

\section{Publish your work in this journal}

Integrated Pharmacy Research and Practice is an international, peer-reviewed, open access, online journal, publishing original research, reports, reviews and commentaries on all areas of academic and professional pharmacy practice. This journal aims to represent the academic output of pharmacists and pharmacy practice with particular focus on integrated care. All papers are carefully

\section{Dovepress}

peer reviewed to ensure the highest standards as well as ensuring that we are informing and stimulating pharmaceutical professionals. The manuscript management system is completely online and includes a very quick and fair peer-review system, which is all easy to use. Visit http://www.dovepress.com testimonials.php to read real quotes from published authors. 